\title{
FINGER CONTRACTURES DUE TO TENDON LESIONS AS A MODE OF PRESENTATION OF RHEUMATOID ARTHRITIS
}

\author{
BY \\ B. M. ANSELL and E. G. L. BYWATERS \\ From the Special Unit for Juvenile Rheumatism, Canadian Red Cross Memorial Hospital, Taplow, \\ Maidenhead, Berks, and the Department of Medicine, Postgraduate Medical School, University of London
}

(RECEIVED FOR PUBLICATION SEPTEMBER 8, 1953)

Contractures of the fingers producing a claw hand may be due to nerve lesions (ulnar palsy), muscle lesions (haemophilia or traumatic Volkman's contracture and dermatomyositis), skin lesions (scleroderma), fascial lesions (Dupuytren's contracture), joint lesions (rheumatoid arthritis or osteo-arthritis), or lesions of the tendons and tendon sheaths. The most common lesion of the tendon is a traumatic thickening leading to the 'snapping finger, usually single, occasionally multiple, and often related to occupation. In gout, uric acid accumulations may occur in the tendon, producing limitation or even "ankylosis" of the fingers without the joints themselves being involved. In rheumatic fever, nodules may form in the tendons of the palm, producing a sticking finger (Scheele, 1885; Keil, 1938; Berkowitz, 1912), but these invariably straighten out again without residue in the course of a few days or weeks (Bywaters, 1951). Similar contractures occur in the palindromic type of rheumatoid arthritis (Bywaters, 1949), and in cases of lupus erythematosus. These reversible contractures need no special therapeutic measures. In rheumatoid arthritis, however, tendon lesions are not only common, occurring in 48 per cent. of cases (Helweg, 1924), 47 per cent. (Edström, 1945), or 42 per cent. (Kellgren and Ball, 1950), but are of the greatest importance from the therapeutic viewpoint. Left untreated, they not only produce such limitation of finger extension that the patient becomes severely handicapped, but, after a time, they may become irreversible through secondary changes in other tissues. It is, therefore, important from the practical aspect to recognize these changes early. While there is little difficulty in their recognition in a frank case of rheumatoid arthritis, it is perhaps rather more difficult to diagnose the tendinous lesions of rheumatoid arthritis in the absence of arthritis. This paper, therefore, describes three cases where the tendon lesions were the presenting sign and joint lesions were either absent or asymptomatic and minimal. A fourth case where joint lesions preceded tendon involvement is included for the discussion of treatment.

The methods used to assess the results of treatment included measurements of gripping strength (Ansell and Bywaters, 1952) and of the palmar contact area. To obtain the latter the palmar aspect of the hand was well inked and then pressed firmly on to paper secured on a flat table. The inked area was then measured with a planimeter.

\section{Case Reports}

Case 1.-This girl was admitted in March, 1952, because of inability to straighten her fingers.

In December, 1951, when aged 16, she developed painless swelling of the dorsum of each hand, followed some 10 days later by swelling of the ankles and dorsa of the feet. Shortly afterwards she had aching in the wrists with paraesthesia of the fingers and the swelling of the left hand became much worse. The swelling of the hands and feet gradually subsided without any specific therapy, but as this happened the patient noticed stiffness of the fingers and inability to straighten them; this was 3 weeks before admission and 2 months from onset.

At the age of 6, during an attack of enteritis, a murmur had been noted in the heart, because of which she was sent to a special school. She had, however, no other symptoms and there had been nothing suggestive of rheumatic fever or chorea.

Examination.-There was slight generalized swelling along the whole length of the fingers, fullness of both dorsal sheaths, $40^{\circ}$ limitation of dorsiflexion of the wrists and inability to straighten the fingers. There was no detectable synovial thickening, fluid, or pain, either in the fingers or elsewhere. The spleen was palpable but there was no lymphadenopathy, rash, or nodule formation.

Cardio-vascular System.-The apex beat was of a left ventricular character. There was a systolic thrill in the vessels of the neck and a harsh basal systolic murmur was heard which was well conducted to the apex. There was also a short aortic diastolic murmur. The blood pressure was $150 / 65$. The chest $x$ ray showed a prominent left ventricle with a small aortic arch. There was also a bifid fourth rib. Dr. Paul Wood considered that these 
findings indicated most probably a congenital aortic lesion.

Laboratory Investigations.-

Erythrocyte sedimentation rate $25 \mathrm{~mm}$. $/ \mathrm{hr}$ (Wintrobe).

Differential agglutination titre for sheep red cells $1: 32$ (positive).

Radiological Examination.-Hands and wrists showed no abnormality.

Biopsy.-The wrist joint showed hyperplasia of the lining membrane with an increase in the number of capillaries, and marked infiltration with lymphocytes and plasma cells, with some polymorphonuclear cells, consistent with rheumatoid arthritis. The dorsal tendon sheath showed similar but more marked changes (Fig. 1).

Diagnosis.-She was thought to be suffering from mild rheumatoid arthritis of the tendinous variety with minimal asymptomatic wrist joint involvement.

Treatment.-She was given wax baths and exercises, and gradually improved during the first 7 months, so that by September, 1952, she was able to resume her normal work though there was still slight limitation of finger extension.

Result.-By June, 1953, no abnormality could be detected, and the erythrocyte sedimentation rate was $19 \mathrm{~mm}$./hr. This improvement is shown in the serial palm prints (Fig. 2).

Case 2.-This girl was first seen in 1950, when aged 12, complaining of inability to straighten the fingers.

When 2 years of age she had developed pain and swelling of the knees and hands, stiffness of the neck, and general malaise necessitating admission to hospital. These signs persisted for about 3 months, but eventually subsided after an attack of measles, leaving no residua.

She remained well until the age of 8 years (1946) when difficulty in straightening the right fifth finger was noted. During the next 2 years other fingers became similarly affected. In March, 1948, she saw her doctor because of tonsillitis and he made a diagnosis of rheumatoid arthritis. Her erythrocyte sedimentation rate was then

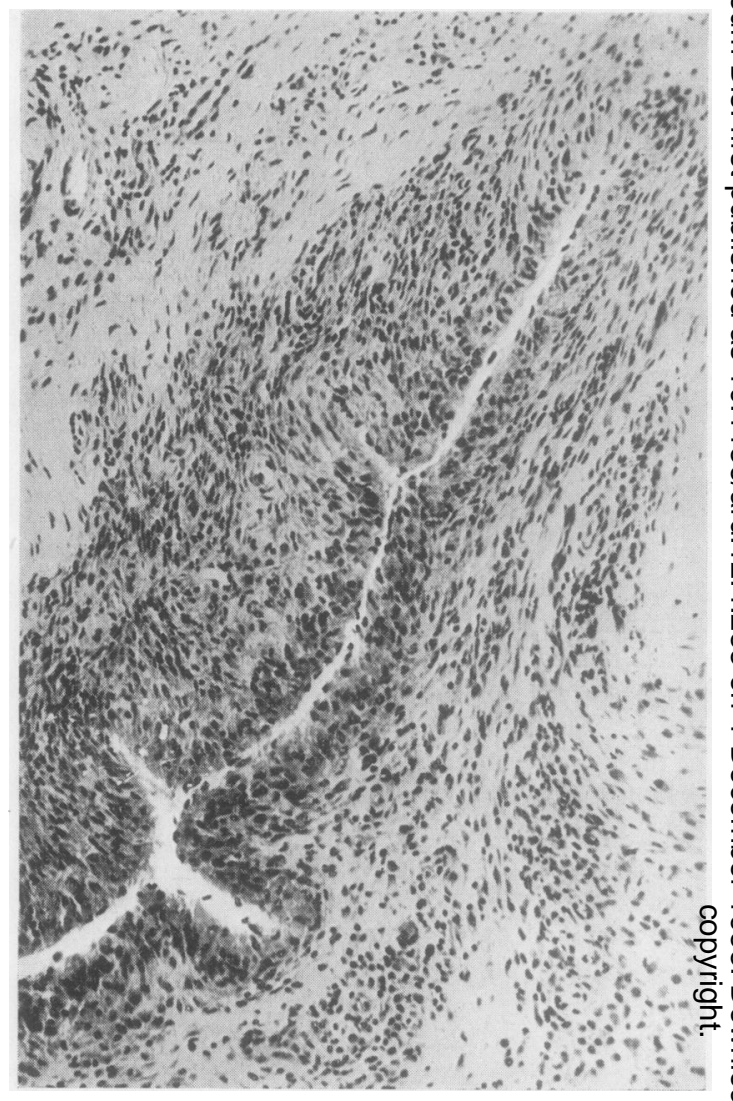

Fig. 1.-Case 1, biopsy of dorsal tendon sheath showing hyperplasia of the lining membrane, increase in capillaries, and marked cellular infiltration.

$45 \mathrm{~mm}$./hr (Westergren). A course of gold injections was stopped after 11 weeks because of the development of a

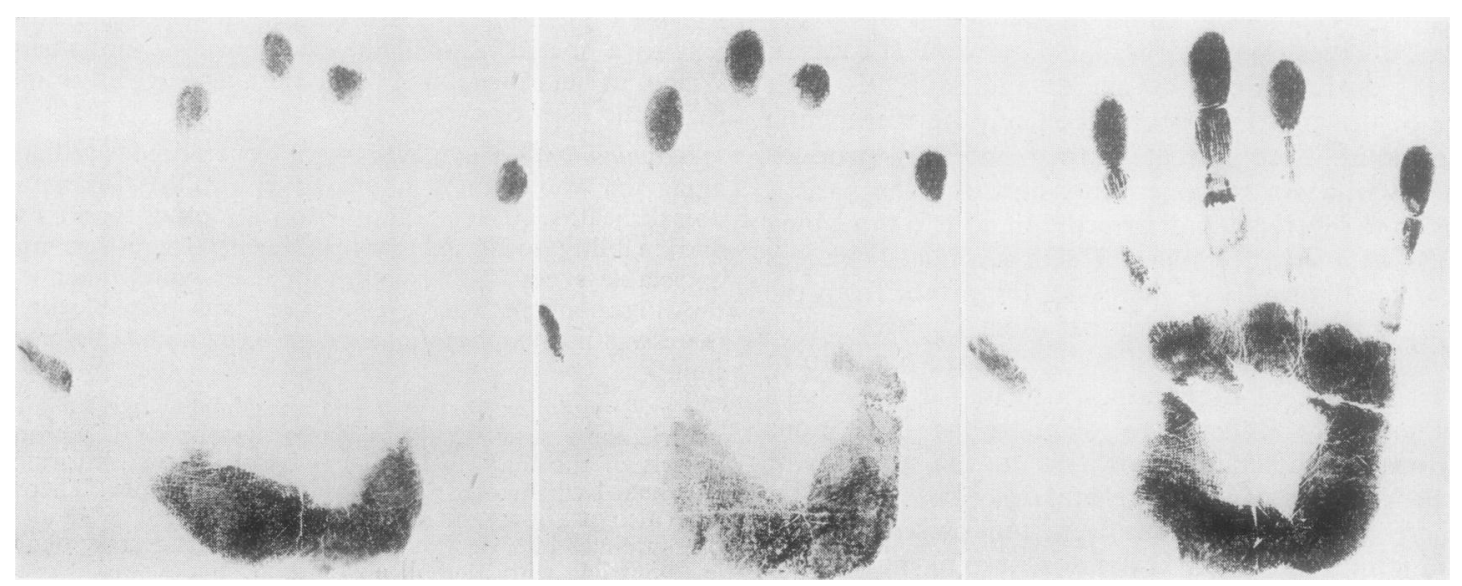

Fig. 2.-Serial palm prints in Case 1, showing improvement. 

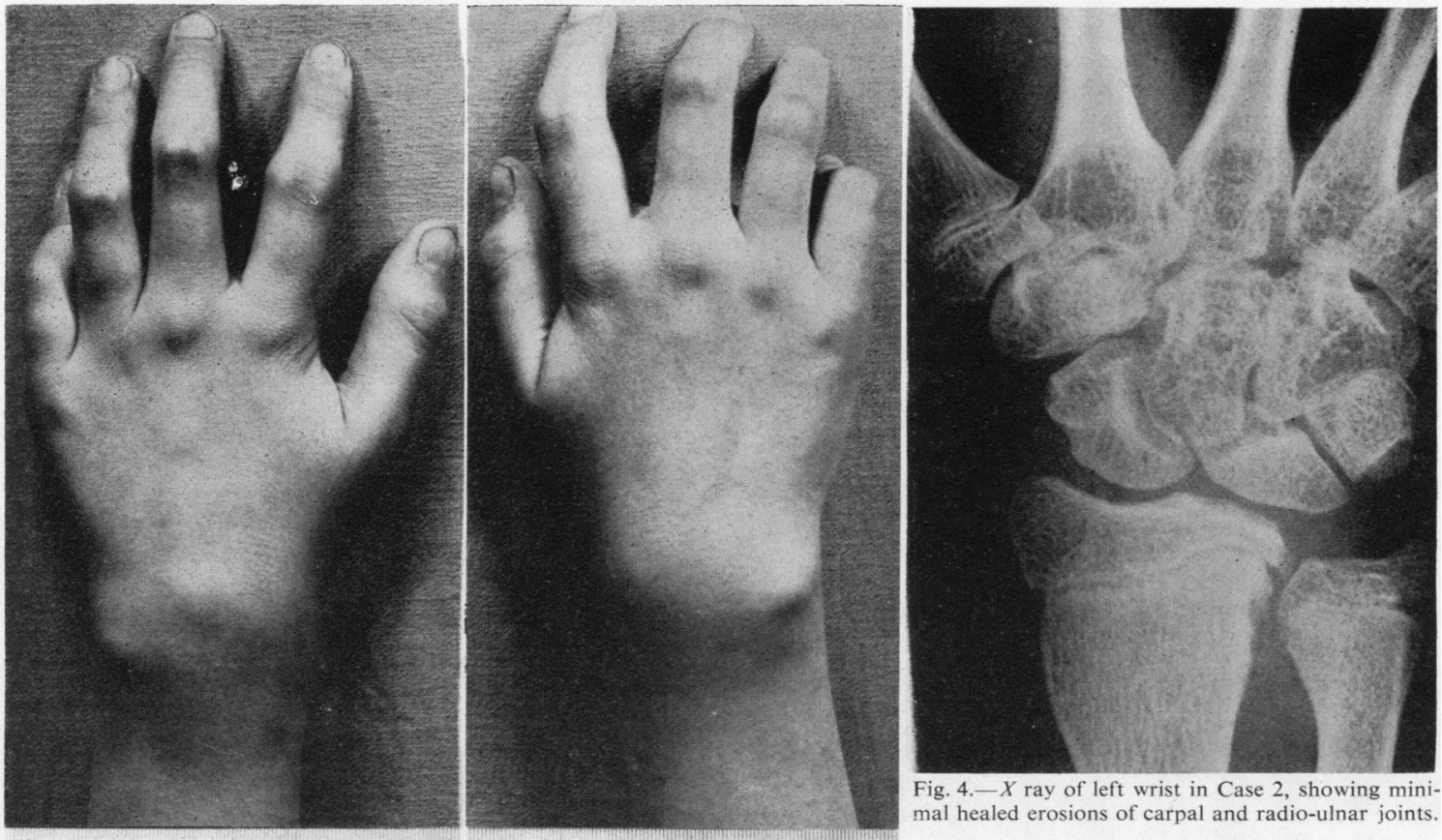

Fig. 4.- $X$ ray of left wrist in Case 2, showing minimal healed erosions of carpal and radio-ulnar joints.

Fig. 3.-Flexion deformities of fingers in Case 2 .

rash; it had produced no improvement in the finger contractures, which during the next 2 years appeared to increase. There was no pain at all throughout this period.

Examination.-In June, 1950, she showed limitation of extension of all her fingers with thickening of the tendons in the palms (Fig. 3). In addition there was slight swelling over the flexor tendon sheath on the right internal malleolus. There was no pain, and no evidence of joint involvement, nor was there any lymphadenopathy, splenomegaly, rash, or palpable nodules.

Laboratory Investigations.-

Erythrocyte sedimentation rate $9 \mathrm{~mm}$./ hr (Wintrobe).

Differential agglutination titre for sheep red cells was $1: 2$

Radiological Examination.--Hands and wrists showed some growth deformity of the right and left radial and ulnar epiphyses with minimal healed erosions of both carpi and the radio-ulnar joints (Fig. 4).

Diagnosis.-The patient was thought to have suffered from mild subclinical arthritis of the rheumatoid variety which was now inactive.

Treatment.-Exploration and mobilization of the flexor tendon sheaths of the left hand was done by $\mathrm{Mr}$. Jenkins in October, 1950, at the Postgraduate Medical School, and in May, 1951, a similar procedure was carried out on the right hand. The material removed at operation showed granulomatous infiltration of mesotenon and marked involvement of peritenon with fibrin accretion, palisading, and cellular infiltration. No necrosis was seen (Fig. 5).
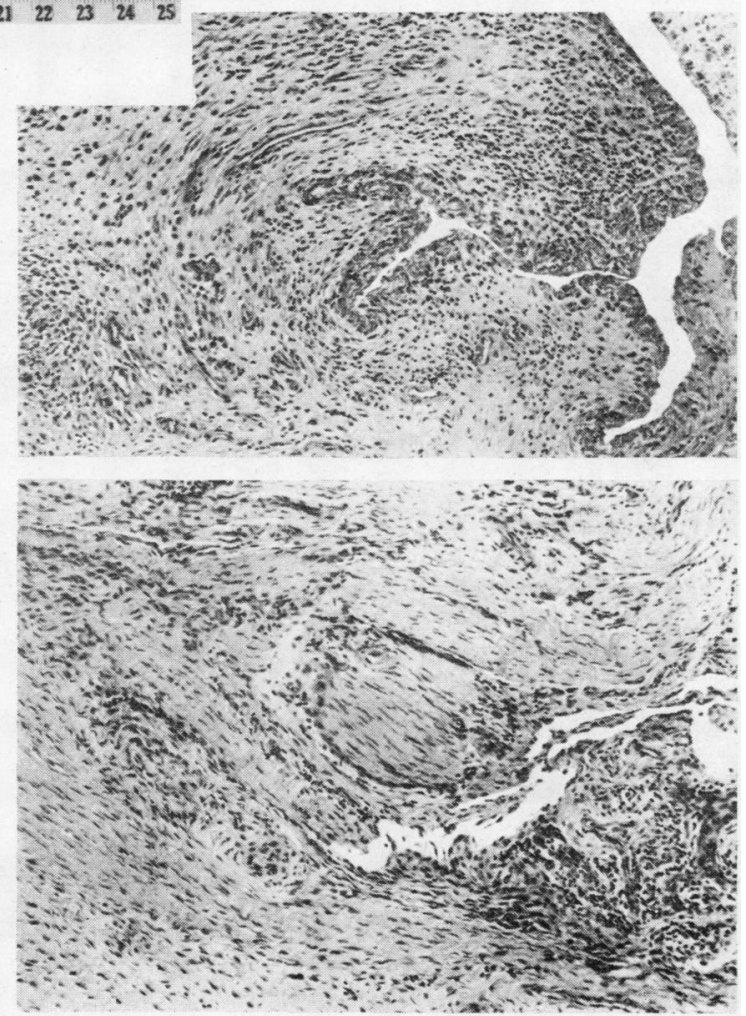

Fig. 5.-Biopsv of tendon in Case 2, showing infiltration of mesotenon and marked involvement of peritenon. 
Result.- The operation on the left side was followed by marked improvement in position and ability to use the hand, and this improvement has been maintained to date. On the right, however, although the patient is able to use the hand better, the flexion contractures of the 4th and 5 th digits are not greatly changed. This is shown in the serial palm prints (Fig. 6).

Case 3.-This girl was first seen in August, 1952, when aged 12 , because of stiffness of the hands.
The onset of the disease was in May, 1952, with swelling and pain in both ankles, which interfered with walking and running. This persisted for 2 weeks, after which there was only slight aching, but one month later she noticed transient pain on using her hands. Shortly after this it was noticed that the fingers would not straighten.

There was nothing relevant in the past history. Her mother had had rheumatic fever for 3 months at the age of 16 , but without sequelae.

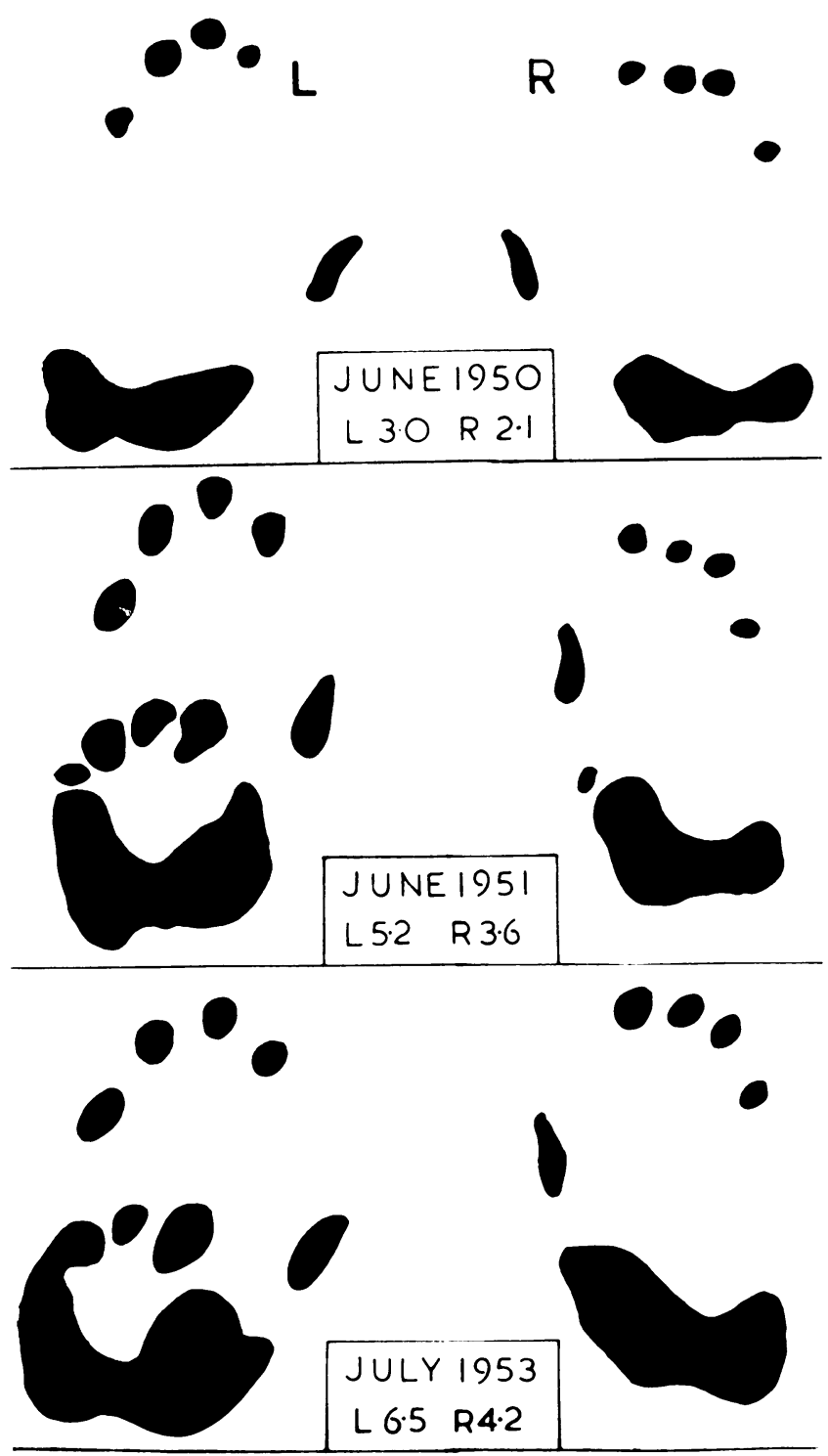

Fig. 6.-Serial palm prints in Case 2, showing improvement in area of contact (measured in square inches).
Examination.-There was thickening of all the palmar digital tendons with inability to straighten the fingers and pain on full flexion. $\vec{\omega}$ Both the wrists showed $35^{\circ}$ limitation and dorsiflexion, but this was painless. The left elbow was slightly painful on movement and 으 lacked $5^{\circ}$ of extension. All other joints includ- $\vec{N}$ ing the ankles appeared normal. There were no $\rightarrow$ nodules, lymphadenopathy, splenomegaly, or $\mathrm{N}$ rash. Other systems showed no abnormality.

\section{Laboratory Investigations.-}

Erythrocyte sedimentation rate $20 \mathrm{~mm}$./hr (Wintrobe).

Differential agglutination titre for sheep red cells $1: 4$ (negative).

Radiological Examination.-Hands, wrist and feet no abnormality.

Diagnosis.-Rheumatoid arthritis of the tendinous variety.

Therapy.-She commenced wax baths and $\stackrel{\mathbb{2}}{2}$ exercises, but the hands did not improve.

Progress.-In October, 1952, she had a severe attack of pain and swelling of the ankles, lasting 2 weeks. By November, the flexion deformity of all the fingers had increased, there was marked nodular thickening in the flexor $\frac{\sigma}{3}$ and extensor tendons of the fingers (Fig. 7, opposite), round the elbow, in the extensor of tendons of the toes, and in both Achilles tendons. Apart from limitation of wrist movement $\mathrm{O}$ all the joints were normal and no other abnormalities could be detected. The patient was admitted to hospital.

Laboratory Studies.-

Erythrocyte sedimentation rate $18 \mathrm{~mm}$./ hr $\omega$ (Wintrobe), rising to $20,25,37$, and 43 $\mathrm{mm}$./hr over the next 6 weeks.

Total leucocyte count 6,000 , normal differ- $\stackrel{0}{\frac{C}{C}}$ ential.

No L.E. cells present in peripheral blood.

Differential agglutination titre $1: 4$ (negative). 


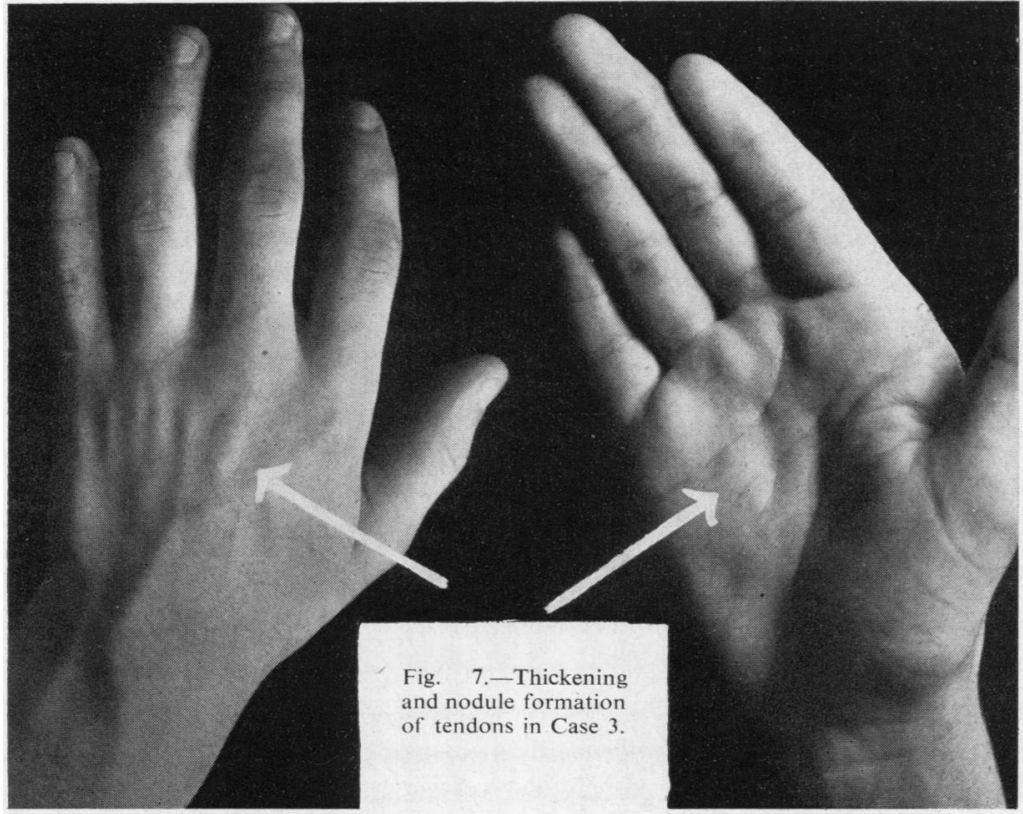

Radiological Examination.No abnormality.

Biopsy.-Left elbow nodule consistent with juvenile rheumatoid arthritis.

Therapy.-She was initially treated by night splintage of the hands and intensive physiotherapy as before, with only a slight improvement. The contractures had now lasted for 5 months, so it was decided to give adrenocorticotrophic hormone. $80 \mathrm{mg}$. per day for 16 days produced marked improvement in the position of the fingers and decrease of thickening of the tendons (Fig. 8). Despite sodium restriction, fluid retention occurred, and therefore corticotrophin was gradually decreased and stopped

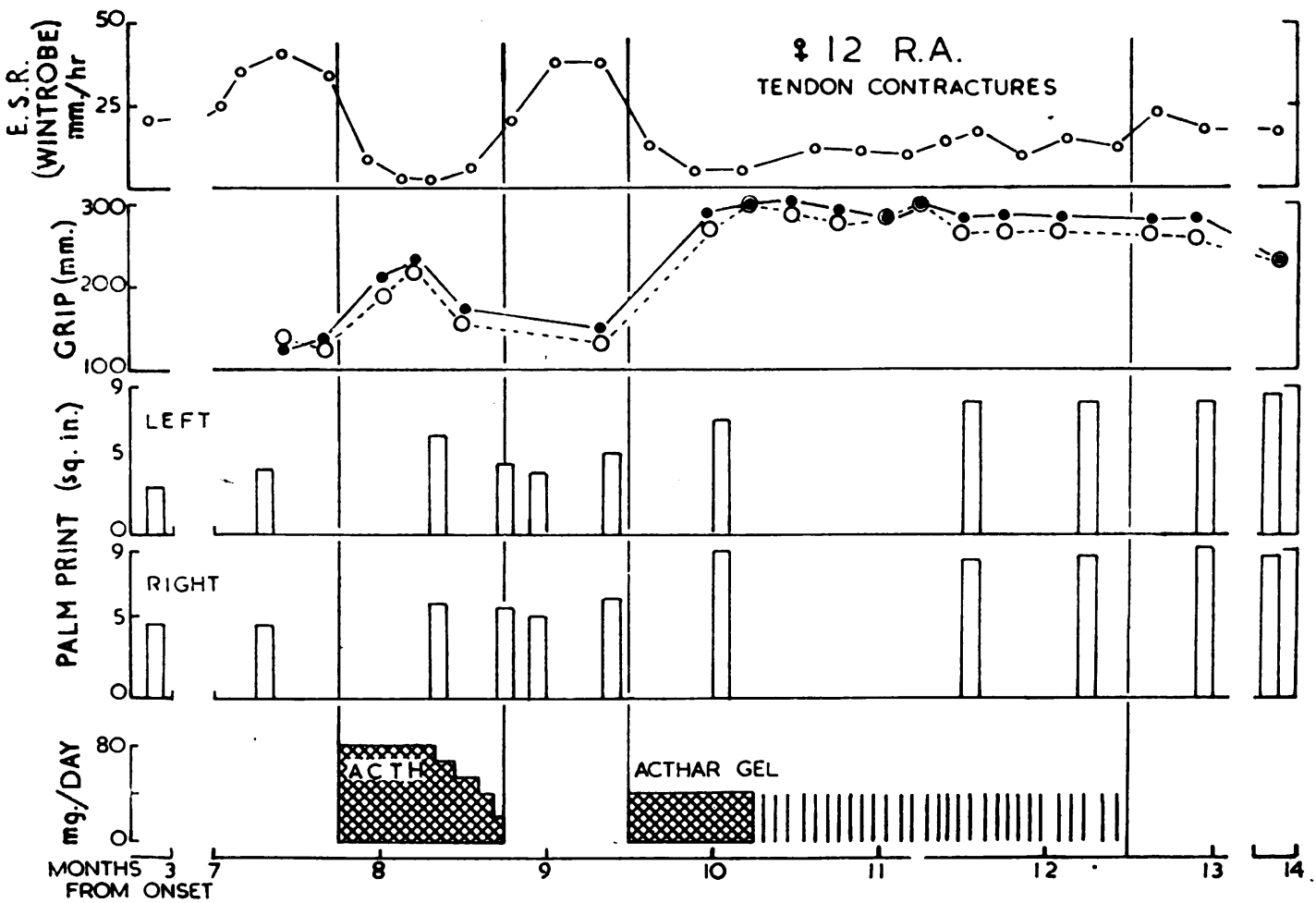

Fig. 8.-Chart showing response to corticotrophin thếrapy in Case 3. Note improvement initially in area of palm print, grip, and E.S.R. with relapse on cessation of therapy and subsequent remission with a further course. 
after a total of $1.7 \mathrm{~g}$. during 30 days. Cessation was followed by a marked increase of nodule formation along both Achilles tendons and round the ankles. There was slight deterioration in the strength of the grips, but little change in the position of the hand. The erythrocyte sedimentation rate, which had fallen to $2 \mathrm{~mm}$./hr, rose to $30 \mathrm{~mm}$./hr (Wintrobe). A second biopsy now taken from the Achilles tendon showed a similar picture to the previous one, except there was slight palisade formation and considerably more cellular infiltration.

Intensive physiotherapy was continued but, as there was no improvement over the following 6 weeks, she was given Acthar gei. In the first 3 weeks, on $40 \mathrm{mg} . / 24 \mathrm{hrs}$, she rapidly improved, and when the dosage was gradually decreased there was no relapse. The hormone was continued for 3 months, a total of $4.2 \mathrm{~g}$. being given. At the end of therapy there persisted some nodular thickening of both Achilles tendons and one definite nodule of the left elbow. During the period of therapy she had had slight swelling of the dorsal sheaths of both wrists for 5 days, and definite arthritis of the right talonavicular joint lasting 3 days.

Result.-Three months after therapy ended there had been a mild erythrocyte sedimentation rate relapse, but there was no functional disability and no joint involvement, clinically or on radiological examination. Throughout, joint involvement had been minimal and fleeting.

Case 4.- This woman was first seen in 1940, at the age of 24 years, complaining of pain and stiffness of the hands. This had commenced one year previously with pain and swelling of the right index finger, and shortly after of the left index and 5th fingers. In the 2 months prior to attendance she had had occasional pain and swelling of the wrists and hands.

Examination.-In July, 1940, the only abnormality was arthritis of the left 5 th proximal interphalangeal and of the left 2 nd metacarpophalangeal joints.

Laboratory Investigations.-

Erythrocyte sedimentation rate $20 \mathrm{~mm}$. $/ \mathrm{hr}$ (Wintrobe).

Radiological Examination.- Hand showed no abnormality.

Therapy.-She was treated with wax baths to the hands and salicylates by mouth with definite improvement, so that 3 months later she was symptom-free, but for the first time a nodule was noted on the right 2 nd proximal interphalangeal joint.

Progress.-She continued to do full-time clerical work, but through the next 7 years there was a gradual increase in her arthritis and she also noticed development of nodules on the hands. About this time she began to get marked stiffness of the hands and by 1950 she was unable to use her fingers satisfactorily because of nodules in the palmar tendons.

Laboratory Studies.-

Erythrocyte sedimentation rate $13 \mathrm{~mm}$./hr (Wintrobe). Differential agglutination titre $1: 128$.
Radiological Examination.-Left hand showed a heale $\stackrel{\Phi}{T}$ erosion (well calcified) and narrowing of the joint spaces in the left second metacarpophalangeal joint, wit $\vec{\xi}$ reduction of the joint space and cyst formation in the left carpus.

Operation.-The rheumatoid process was thought to b\& quiescent, and in 1950 the flexor tendon sheaths were incised by Mr. S. A. Jenkins at the Postgraduate Medica् School, and free movement of the tendons obtained. biopsy of the third finger tendon showed fibrinoig necrosis in the wall of the tendon sheath, with conside able cellular reaction mainly of a macrophage type.

Result.-At the time of review in 1953, she felt that her hands had been much improved by the operation, and she् had no exacerbation of the arthritis. She showed residua joint changes in the left elbow, both wrists, and bot 3rd metacarpophalangeal joints, with some nodule formation along the left big toe and left heel.

\section{Discussion}

The tendinous lesions of rheumatoid arthritiso described first by Helweg (1924) from Copenhagen. have been fully discussed by Kellgren and Ball (1950 with particular reference to pathology and treaf ment. We can agree with those authors on the basis of these and other cases that the dominant change is the appearance of granulation tissue and fibrosis. in the mesotenon and peritenon accompanied की necrosis, often fibrinoid, of the tendon fibres orsos the granulation tissue and in some instances reseme bling the ordinary subcutaneous nodule. In the first three cases described above, the contracture was the presenting lesion, and occurred sometimeso within 2 months (Case 1) or 6 weeks of onset (Case 39 and sometimes later (Case 2), and either wit (Case 3) or without (Cases 1 and 2) nodule formation in the subcutaneous tissues. In the absence of raised erythrocyte sedimentation rate (Case 2) of raised differential agglutination titre (Cases 2 and 3 ) it is important to distinguish this type of case frorg scleroderma. Although the skin appears smooth duo to lack of use, it is neither thickened nor bound down; telangiectases are not seen nor is there los of pulp or bone in the terminal phalanx.

The treatment initially and of early cases essentially mobilization of the fingers by active and passive movement after wax baths. The excellen results in Case 1 can be easily seen in the serial palp prints. Sometimes it is necessary to use nighึ splints to maintain good finger posture. In a mores severe case (Case 3), Acthar gel produced a striking improvement, although the subcutaneous nodule od the elbow failed to disappear. In long-standing cases surgical action is necessary, and this usually produces an improvement (Cases 2 and 3), although this mase not be lasting (Case 2). 


\section{Summary}

(1) Three cases of rheumatoid arthritis presenting as flexion contractures of the fingers are described.

(2) The histological changes in the tendons are typical of rheumatoid arthritis.

(3) Conservative treatment in the form of physiotherapy and corticotrophin was valuable in the two early cases, whereas, in the third case and in a fourth case also observed, freeing of the tendons by surgical operation greatly improved function.

We wish to thank Dr. Harwood Stevenson and Mr. G. Platt who kindly referred Cases 1 and 3, as well as the other doctors who referred cases to us, and Messrs. P. Fiske and R. Brewer who were responsible for the photographs.

\section{REFERENCES}

Ansell, B. M., and Bywaters, E. G. L. (1952). Annals of the Rheumatic Diseases, 11, 213.

Berkowitz, R. (1912). Arch. Kinderheilk., 59, 1.

Bywaters, E. G. L (1949). Annals of the Rheumatic Diseases, 8, 1.

(1951). "Modern Practice in Infectious Fevers", ed. H. S. Banks, vol. 1, p. 156. Butterworth, London.

Edström, G. (1945). Nord. Med., 25, 379.

Helweg, J. (1924). Klin. Wschr., 3, 2383.

Keil, H. (1938). Medicine, Baltimore, 17, 261.

Kellgren, J. H., and Ball, J. (1950). Annals of the Rheumatic Diseases, $9,48$.

Scheele, ??. ??. (1885). Dtsch. med. Wschr., 11, 702.
Contractures digitales dues aux lésions tendineuses comme mode de présentation de l'arthrite rhumatismale

\section{RÉSUMÉ}

(1) On décrit trois cas d'arthrite rhumatismale se manifestant sous forme de contractures digitales en flexion.

(2) Les lésions histologiques des tendons sont typiques de l'arthrite rhumatismale.

(3) Un traitement conservateur sous forme de physiothérapie et de corticotrophine s'avéra utile dans les deux premiers cas, tandis que dans le troisième (et dans un quatrième aussi examiné), la libération chirurgicale des tendons produisit une amélioration considérable de la fonction.

\section{Contracturas digitales debidas a lesiones tendinosas como} modo de presentación de la artritis reumatoide

\section{SUMARIo}

(1) Se describe tres casos de artritis reumatoide manifestándose como contracturas digitales en flexión.

(2) Las lesiones histológicas tendinosas son típicas de artritis reumatoide.

(3) Un tratamiento conservatorio en forma de fisioterapia y de corticotrofina fué útil en los dos primeros casos, mientras que en el tercero ( $\mathrm{y}$ en un cuarto caso también examinado), la liberación quirúrgica de los tendones produjo una mejoría considerable de la función. 